\title{
Osteoporosis - Relationship of Bone Mass Density with Body Mass Index and Selected Variables: A Descriptive Survey
}

\section{Athar Javeth*}

Department of Medical Surgical Nursing, AIIMS Patna, Bihar, India

*Corresponding Author: Athar Javeth, Department of Medical Surgical Nursing, AIIMS Patna, Bihar, India.
Received: July 17, 2020

Published: August 28, 2020

(C) All rights are reserved by Athar Javeth.

\section{Abstract}

Background: Osteoporosis is a silent thief of bone which is characterized by decreased bone mass density and gradual decline in bone tissue which increases the susceptibility to bone fracture. The objective of the study is to assess the bone mass density and body mass index and to find out the relationship between them.

Materials and Methods: A quantitative approach with descriptive survey design was used to find out the relationship between BMD and BMI and association of BMD with selected variables. A total of 100 people from general public were selected using convenient sampling. Structured questionnaire was used to collect the information about associated risk factors and BMI was calculated after measuring weight and height of the samples. Ankle Bone mass density was measured using ultrasound bone densitometer.

Results: The overall mean of BMD and BMI were $-1.91 \pm 1.47$ (95\% CI -2.202 - -1.618) and $25.38 \pm 4.33$ (24.52 - 26.27$)$ respectively. A maximum of $43 \%$ of people were having osteopenia and $35 \%$ were having osteoporosis. The mean of age was $44.97 \pm 12.257$ (95\% CI 42.54 - 47.40). The mean of weight and height are $64.39 \pm 12.32$ (95\% CI 61.95 - 66.83) and $159.24 \pm 9.27$ (95\% CI 157.4 - 161.08) respectively. A total of $44 \%$ were in the range of normal BMI. There was a nonsignificant weak positive correlation between Bone mass density and body mass index $(r=0.088)$ and significant negative correlation between bone mass density and age $(r=-2.72)$ at $p<0.05$ level. There was a significant association between smoking and Bone mass density $\left(\chi^{2}=7.241\right.$ at $\left.\mathrm{df} 2\right)$ at $\mathrm{p}<0.05$ level. Conclusion: The findings of study necessitate the need for early identification of osteoporosis by measuring BMD and prompt treatment and thereby improve the quality of life of people.

Keywords: Osteoporosis; Bone Mass Density; Body Mass Index; Survey

\section{Abbreviations}

BMD: Bone Mass Density; BMI: Body Mass Index

\section{Introduction}

Osteoporosis is a silent thief of bone which is characterized by decreased bone mass density and gradual decline in bone tissue which increases the susceptibility to bone fracture [1]. The subclinical nature of oosteoporosis i.e. clinically silent may predispose to increased risk of fractures [2], increased morbidity, mortality and associated reduced quality of life. Moreover, it widens the disability adjusted life span and additional financial burden to the health care system [3]. Osteoporosis is a chronic disorder which affects the microarchitecture of bone and results in decreased mineralization. It is an underdiagnosed and under treated disease [4].

Osteoporosis is a serious health problem of the public. According to International Osteoporosis Foundation, there are 75 mil- 
lion people who are affected by osteoporosis in United States of America, Europe and Japan. During the lifetime $40 \%$ of women and $15-30 \%$ of men will get one or more fractures [5]. Worldwide osteoporosis causes fracture in every 3 seconds which contributes to 8.9 million fractures in a year. Over the age of 50 years, 1 in 3 women and 1 in 5 men experiences osteoporotic fractures. It was estimated that $61 \%$ of fractures associated with osteoporosis take place in women with female to male ratio 1.6 [6]. People who had a history of fracture are at an increased risk (80\%) of predisposition to fracture [5].

In Asia, it is predicted that more than $50 \%$ of all hip fractures related to osteoporosis is likely to occur by the year 2050. High risk patients to osteoporosis are those, who had already a history of fractures and living in rural areas [5]. Shatrugna V., et al. (2005) conducted a study to determine the prevalence of osteoporosis in 289 women who are in the age group of $30-60$ years. It was found that improper nutrition was thought to be the reason for $29 \%$ prevalence rate of osteoporosis and high prevalence rate of osteopenia i.e. $52 \%$. Comparing with developed countries population, Bone mineral density was lower in all skeletal sites [6]. A study was conducted by Kadam SN., et al. (2018) to determine the prevalence of osteoporosis in 421 healthy adults in Pune city of India. There was a rapid decline in BMD for postmenopausal women and gradual decline in men. BMD T scores were significantly lower in men compared to premenopausal women but not with postmenopausal women. Indian postmenopausal women and men are highly susceptible to osteoporosis [7].

According to Guidelines of Osteoporosis by AACE, risk factors of osteoporosis include advancing age, decreased body weight less than $57.6 \mathrm{~kg}$, smoking, early menopause, excess alcohol intake greater than 3 drinks per day, family history, rheumatoid arthritis, use of glucocorticoid medications and secondary osteoporosis [8].

Aging process results in gradual and progressive loss of bone mineral density altering the structure, composition and function of bone [9]. With the increased research evidence and related literature, it was concluded that osteoporosis is a preventable and manageable [10]. Therefore, osteoporosis can be early diagnosed and treated with the help of assessment of Bone mineral density and by such means preventing the fractures associated with it. It is also recommended to adopt appropriate measures to prevent the occurrence of osteoporosis prior to later years of life in both men and women.

Hence the study was conducted to assess the bone mass density and determine its relationship with body mass index and other selected variables.

\section{Materials and Methods}

A descriptive survey design was used to assess the bone mass density and its relationship with body mass index and the selected variables of patients attending the outpatient department of Medicine of Mother Hospital, Thrissur. A formal administrative approval was obtained from the Head of the Institution prior to data collection. Subjects consisting of 100 patients attending the outpatient department of Medicine were recruited using convenient sampling. The tool for data collection was structured questionnaire for the collection of socio-demographic data and Ultrasound bone densitometer was used to determine the bone mass density. Peripheral heel bone density was measured using ultrasound modality with the help of machine bone densitometer. According to World Health Organization WHO, T score is the basis of interpretation of bone mass density. T Score of more than -1 is normal, -1 to -2.5 is considered as osteopenia and -2.5 and below is interpreted as osteoporosis. It is convenient, radiation free, safe and simple technique of assessing the precise quantitative status of bone status. Weight and standing height was measured using calibrated weighing scale and inch tape respectively. Body mass index was calculated using the formula of weight in $\mathrm{Kg} /$ Square of height in meters. Informed consent was taken prior to data collection was taken and the purpose of study was explained and confidentiality was assured. The subject were given the structured questionnaire containing items related to socio-demographic data and BMD was measured using ultrasound bone densitometer in the sitting position. Ten to fifteen minutes were taken to collect data. The procedure for data collection was satisfactory. Analysis of data was done using descriptive and inferential statistics. Frequency, percentage distribution, mean and standard deviation was calculated for bone mass density and body mass index. Pearson Product Moment correlation (r) was employed to determine the relationship of bone mass density and continuous variables such as body mass index, weight, height and age. Chi-square was computed to analyse the association of the bone mass density with discrete variables such as gender, habit of smoking, past history of fracture, rheumatoid arthritis and menopause and calcium intake. 


\section{Results}

Sociodemographic characteristics

Major portion of subjects (43\%) were osteopaenic (-1.91 \pm 1.47 , $95 \%$ CI $-2.202-1.618)$. Most of the patients (46\%) were having normal BMI (25.38 $\pm 4.33,95 \%$ CI 24.52 - 26.27). The mean of age was $44.97 \pm 12.257$ (95\% CI $42.54-47.40)$. The mean of weight and height are $64.39 \pm 12.32$ (95\% CI 61.95 - 66.83) and $159.24 \pm 9.27$ (95\% CI 157.4 - 161.08) respectively. The frequency and percentage distribution of the study subjects were depicted in the table 1.

\begin{tabular}{|c|c|c|c|c|c|}
\hline Variables & Categories & $\mathbf{f}$ & $\%$ & Mean (SD) & $95 \% \mathrm{CI}$ \\
\hline \multirow{3}{*}{ BMD } & -1 and above (Normal & 20 & 20 & \multirow{3}{*}{$-1.9(1.47)$} & \multirow{3}{*}{$-2.202--1.618$} \\
\hline & -2.5 to -1 (osteopenia) & 43 & 43 & & \\
\hline & -2.5 and below (osteoporotic) & 37 & 37 & & \\
\hline \multirow{4}{*}{ BMI } & $<18.5$ (Underweight) & 4 & 4 & \multirow{4}{*}{$25.38(4.33)$} & \multirow{4}{*}{$24.52-26.27$} \\
\hline & 18.5 - 24.99 (Normal) & 46 & 46 & & \\
\hline & 25 - 30 (Overweight) & 34 & 34 & & \\
\hline & 30 and above (Obese) & 16 & 16 & & \\
\hline \multirow{4}{*}{ Weight } & $30-50$ & 12 & 12 & \multirow{4}{*}{$64.39(12.32)$} & \multirow{4}{*}{$61.95-66.83$} \\
\hline & $50-70$ & 57 & 57 & & \\
\hline & $70-90$ & 29 & 29 & & \\
\hline & 90 and above & 2 & 2 & & \\
\hline \multirow{2}{*}{ Height } & Below 159 (median) & 53 & 53 & \multirow{2}{*}{$159.24(9.27)$} & \multirow{2}{*}{$157.4-161.08$} \\
\hline & Above 159 (median) & 47 & 47 & & \\
\hline \multirow{4}{*}{ Age } & $15-30$ & 17 & 17 & \multirow{4}{*}{$44.97(12.26)$} & \multirow{4}{*}{$42.54-47.40$} \\
\hline & $30-45$ & 28 & 28 & & \\
\hline & $45-60$ & 45 & 45 & & \\
\hline & $60-75$ & 10 & 10 & & \\
\hline \multirow{2}{*}{ Prior Fracture } & Yes & 23 & 23 & & \\
\hline & No & 77 & 77 & & \\
\hline \multirow{2}{*}{ Smoking } & Yes & 8 & 8 & & \\
\hline & No & 92 & 92 & & \\
\hline \multirow{2}{*}{ History of RA } & Yes & 19 & 19 & & \\
\hline & No & 81 & 81 & & \\
\hline \multirow{2}{*}{ Menopause attained } & Yes & 26 & 26 & & \\
\hline & No & 74 & 74 & & \\
\hline \multirow{2}{*}{ Intake of Calcium } & Yes & 9 & 9 & & \\
\hline & No & 91 & 91 & & \\
\hline
\end{tabular}

Table 1: Sociodemographic characteristics of patients.

\section{Relationship of BMD with variables}

Relationship was determined according to type of variables i.e. continuous and discrete variables. There was significant negative correlation between age and bone mass density $(r=-.272, p=$
0.006 at $\mathrm{df} 98)$. This indicated that as the age increases there is a significant decrease in the bone mass density. There was a nonsignificant weak positive correlation between bone mass density and body mass index $(r=.088, p=.383$ at $\mathrm{df} 98)$; bone mass density and 
weight ( $\mathrm{r}=.086, \mathrm{p}=.392$ at $\mathrm{df} 98)$; bone mass density and height (at df 98). Relationship between bone mass density and continuous variables is represented in table 2 .

\begin{tabular}{|c|c|c|c|}
\hline Variables & Mean (SD) & $\begin{array}{c}\text { Pearson } \\
\text { Product } \\
\text { moment } \\
\text { Correlation }\end{array}$ & p value \\
\hline BMD & $-1.9(1.47)$ & \multirow{2}{*}{$r=.088$} & \multirow{2}{*}{.383} \\
\hline BMI & $25.38(4.33)$ & & \\
\hline BMD & $-1.9(1.47)$ & \multirow{2}{*}{$r=.086$} & \multirow{2}{*}{.392} \\
\hline Weight & $64.39(12.32)$ & & \\
\hline BMD & $-1.9(1.47)$ & \multirow{2}{*}{$r=.022$} & \multirow{2}{*}{.831} \\
\hline Height & $159.24(9.27)$ & & \\
\hline BMD & $-1.9(1.47)$ & \multirow{2}{*}{$r=-.272^{*}$} & \multirow{2}{*}{$0.006^{*}$} \\
\hline Age & $44.97(12.26)$ & & \\
\hline
\end{tabular}

Table 2: Relationship between bone mass density and continuous variables.

*Significant at 0.01 level.

Chi-square test was done to determine the relationship of bone mass density and discrete variables. There was a significant association between bone mass density and smoking $\left(\chi^{2}=7.24\right.$ at $\mathrm{df}$ 2) at $p<0.05$ level. There was no significant association between bone mass density and other variables such as gender, history of fracture, history of rheumatoid arthritis, menopause attained and intake of calcium supplements. Table 3 represents the relationship between bone mass density and variables.

\section{Discussion}

The present study revealed that there is a weak positive correlation between bone mass density and body mass index. There is a significant negative correlation between age and bone mass density. The study findings were consistent with findings of the study conducted by Bansal A., et al. (2016) with an objective of evaluation of bone mass density in 400 men which also depicted the significant negative correlation between bone mass density and age, and nonsignificant positive correlation between bone mass density and body mass index [11].

The present study revealed that $43 \%$ of subjects were having osteopenia which is consistent with the findings of the study con-

\begin{tabular}{|c|c|c|c|c|c|c|}
\hline Variables & Categories & Yes & No & $\chi^{2}$ & $\begin{array}{c}\mathbf{p} \\
\text { value }\end{array}$ & df \\
\hline \multirow{3}{*}{$\begin{array}{l}\text { BMD and } \\
\text { gender }\end{array}$} & Normal & 13 & 7 & \multirow{3}{*}{1.456} & \multirow{3}{*}{0.483} & \multirow{3}{*}{2} \\
\hline & Osteopenia & 34 & 9 & & & \\
\hline & Osteoporosis & 28 & 9 & & & \\
\hline \multirow{3}{*}{$\begin{array}{l}\text { BMD and } \\
\text { fracture } \\
\text { history }\end{array}$} & Normal & 4 & 16 & \multirow{3}{*}{1.517} & \multirow{3}{*}{0.468} & \multirow{3}{*}{2} \\
\hline & Osteopenia & 8 & 35 & & & \\
\hline & Osteoporosis & 11 & 26 & & & \\
\hline \multirow{3}{*}{$\begin{array}{l}\text { BMD and } \\
\text { smoking }\end{array}$} & Normal & 2 & 18 & \multirow{3}{*}{$7.241^{*}$} & \multirow{3}{*}{$0.027^{*}$} & \multirow{3}{*}{2} \\
\hline & Osteopenia & 0 & 43 & & & \\
\hline & Osteoporosis & 6 & 31 & & & \\
\hline \multirow{3}{*}{$\begin{array}{l}\text { BMD and } \\
\text { rheu- } \\
\text { matoid } \\
\text { arthritis }\end{array}$} & Normal & 0 & 20 & \multirow{3}{*}{5.879} & \multirow{3}{*}{0.053} & \multirow{3}{*}{2} \\
\hline & Osteopenia & 10 & 33 & & & \\
\hline & Osteoporosis & 9 & 28 & & & \\
\hline \multirow{3}{*}{$\begin{array}{l}\text { BMD and } \\
\text { meno- } \\
\text { pause } \\
\text { attained }\end{array}$} & Normal & 5 & 7 & \multirow{3}{*}{0.834} & \multirow{3}{*}{0.656} & \multirow{3}{*}{2} \\
\hline & Osteopenia & 11 & 23 & & & \\
\hline & Osteoporosis & 10 & 19 & & & \\
\hline \multirow{3}{*}{$\begin{array}{l}\text { BMD and } \\
\text { calcium } \\
\text { intake }\end{array}$} & Normal & 1 & 19 & \multirow{3}{*}{0.544} & \multirow{3}{*}{0.762} & \multirow{3}{*}{2} \\
\hline & Osteopenia & 4 & 39 & & & \\
\hline & Osteoporosis & 4 & 33 & & & \\
\hline
\end{tabular}

Table 3: Relationship between bone mass density and discrete variables.

*Significant at 0.05 level.

ducted by Garg N., et al. (2018) with an objective to assess the bone mass density in 332 premenopausal and postmenopausal women. It was found that $45 \%$ of women were having osteopenia which increases the risk for developing the osteoporosis [12]. Age was found to be significantly associated with bone mass density which is also consistent with the present study results.

According to Black D., et al. (2001), fracture risk assessment tool fracture index which comprised of Bone mass density, age weight, smoking status and use of arms to determine the risk factor for developing fracture associated with osteoporosis in 7782 subjects. The present study revealed that bone mass density is significantly associated with smoking of the subjects which is consistent with findings of the study by Black D., et al [13]. 


\section{Conclusion}

Osteoporosis is a silent disease of musculoskeletal system which is characterized by the gradual reduction in bone mass density and increased risk of fractures. Osteoporosis is one of the common public health problem which remains undetected and eventually prone to fractures. Assessment of bone mass density among the general population will supplement in the screening and early diagnosis of osteoporosis. Prompt intervention and preventive measures can be provided and thereby preventing the incidence of fractures and related complications. Researcher recommends for the various cost effective screening methods of bone mass density and identifying the factors contributing to osteoporosis and its preventive measures.

\section{Conflict of Interest}

I have no conflicts of interest to disclose.

\section{Bibliography}

1. Lewis SL., et al. "Lewis's Medical-Surgical Nursing: Assessment and Management of Clinical Problems". Elsevier RELX India Pvt. Ltd. (2018):1467-1470.

2. NIH Consensus Development Panel on Osteoporosis Prevention, Diagnosis, and Therapy. "Osteoporosis Prevention, Diagnosis, and Therapy". JAMA: The Journal of The American Medical Association 285.6 (2001): 785-795.

3. Sözen T., et al. "An overview and management of osteoporosis". European Journal of Rheumatology 4.1 (2017): 46-56.

4. Lems W and Raterman H. "Critical issues and current challenges in osteoporosis and fracture prevention. An overview of unmet needs". Therapeutic Advances in Musculoskeletal Disease 9.12 (2017): 299-316.

5. International Osteoporosis Foundation. Osteoporosis Facts and Statistics (2020).

6. Shatrugna V., et al. "Bone status of Indian women from a lowincome group and its relationship to the nutritional status". Osteoporosis international: a journal established as result of cooperation between the European Foundation for Osteoporosis and the National Osteoporosis Foundation of the USA 16.12 (2005): 1827-1835.
7. Kadam N., et al. "Prevalence of Osteoporosis in Apparently Healthy Adults above 40 Years of Age in Pune City, India”. Indian Journal of Endocrinology and Metabolism 22.1 (2018): 67-73.

8. American Association of Clinical Endocrinologists (AACE) and American College of Endocrinology (ACE)". Clinical Practice Guidelines for the Diagnosis and Treatment of Postmenopausal Osteoporosis (2020).

9. Demontiero Oddom et al. "Aging and bone loss: new insights for the clinician". Therapeutic Advances in Musculoskeletal Disease 4.2 (2012): 61-76.

10. Kling J., et al. "Osteoporosis prevention, screening, and treatment: a review". Journal of Women's Health 23.7 (2014): 563572.

11. Bansal A and Bansal S. "Relationship of Body Mass Index and Bone Mineral Density in Adult Men". International Journal of Medical and Dental Sciences 5.1(2016): 1033.

12. Garg N., et al. "An Epidemiological Study to Assess Bone Mineral Density and Its Association with Contributing Factors among Premenopausal and Postmenopausal Women in Selected Villages of District Shimla, Himachal Pradesh, India". International Journal of Reproduction, Contraception, Obstetrics and Gynecology 7.2 (2018): 487.

13. Black D., et al. "An assessment tool for predicting fracture risk in postmenopausal women". Osteoporosis 12.7 (2001): 519528.

\section{Assets from publication with us}

- Prompt Acknowledgement after receiving the article

- Thorough Double blinded peer review

- Rapid Publication

- Issue of Publication Certificate

- High visibility of your Published work

Website: www.actascientific.com/

Submit Article: www.actascientific.com/submission.php

Email us: editor@actascientific.com

Contact us: +919182824667 